\title{
EL DERECHO AL DEPORTE
}

\author{
ANTONIO MANIATIS \\ Profesor de Derecho Constitucional. \\ Academia de Bomberos, Grecia
}

\begin{abstract}
Resumen: El derecho al deporte es un derecho fundamental, basado sobre el derecho a las asociaciones que pertenece a la primera generación. Se considera como un derecho de segunda generación mientras su versión alternativa de derecho a la educación física comenzó a positivarse constitucionalmente antes de éste. Es posible también considerarse como derecho de tercera generación, a partir del uso explícito del término constitucional "derecho" en 1976. Además, es conectado con el movimiento de los derechos de la cuarta generación. No se trata meramente de un genuino, autónomo derecho fundamental sino también de una garantía institucional y de un conjunto de principios fundamentales de Derecho Constitucional. El derecho al perseguimiento de la felicidad incluye la categoría de derechos a la recreación, ejemplificada por los derechos culturales (cultura, educación) y los derechos al movimiento humano (deporte, turismo - hospitalidad).
\end{abstract}

Palabras clave: derechos fundamentales; heterogeneidad del derecho; educación física; derecho al perseguimiento de la felicidad; deporte.

Abstract: The right to sport is a fundamental one, based on the first generation right to associations. It is considered as a second generation right whilst its alternative version of right to physical education began to be constitutionalized before it. It may be also considered as a $3 \mathrm{G}$ right, from the explicit use of the constitutional term 'right' in 1976 and on. Furthermore, it is connected with the movement of fourth generation rights. It is not merely about an authentic, self-existent fundamental right but also an institutional guarantee and a set of fundamental principles of Constitutional Law. The right to pursuit of happiness includes the category of rights to recreation, exemplified by the cultural rights (culture, education) and the rights to human motion (sport, tourism hospitality).

Keywords: fundamental rights; heterogeneity of law; physical education; right to pursuit of happiness; sport 
SUMARIO: I. INTRODUCCIÓN. II. LA RAMA DEL 'DERECHO DEPORTIVO'. III. EL FENÓMENO DE HETEROGENEIDAD DE PRODUCCIÓN DEL DERECHO. IV. INTERNACIÓN E INTERNALIZACIÓN DEL DERECHO DEPORTIVO POR LA SOCIEDAD. V. LA CONSAGRACIÓN CONSTITUCIONAL IMPLÍCITA DEL DERECHO AL DEPORTE. VI. LA CONSAGRACIÓN CONSTITUCIONAL EXPLÍCITA DEL DERECHO AL DEPORTE: DERECHO DE TERCERA GENERACIÓN. VII. EL DERECHO AL DEPORTE, LOS DERECHOS DE CUARTA GENERACIÓN Y LA PROYECCIÓN DE DERECHOS DE TERCERA GENERACIÓN. VIII. CONCLUSIÓN

\section{INTRODUCIÓN}

Hacer deporte es una actividad muy popular y difundida a nivel internacional. Se trata de un fenómeno social con carácter diacrónico, dado que ya los pueblos de la antigüedad tenían la tendencia de someter sus cuerpos a varios ejercicios físicos, por razones de salud y ocio. Sería interesante examinar el fenómeno deportivo como objeto de regulaciones jurídicas, mucho más como temática particular en el ámbito del derecho público. El presente análisis focaliza sobre la cuestión si hay un único derecho fundamental al deporte.

\section{LA RAMA DEL “'DERECHO DEPORTIVO'}

Las reglas jurídicas sobre los deportes no constituyen una mera legislación sino una rama separada de otras (es decir "autónoma" en ese sentido), confirmada por su reciente codificación, como es el caso del ordenamiento francés ${ }^{1}$. Gracias al reciente desarrollo de este conjunto de regulaciones, la normativa relativa a los deportes ha adquirido una naturaleza avanzada y más madura. Sería posible localizar los siguientes rasgos de la rama del derecho del deporte:

\section{a. Rama especial de derecho}

Según una aproximación ya señalada, las normas sobre los deportes son especiales, focalizadas sobre este fenómeno social. El derecho de los deportes constituye una materia reconocida pero no muy elaborada por la doctrina. En la práctica, los académicos hacen uso de la perífrasis 'Derecho Deportivo', que constituye un término aceptado y práctico, gracias a su brevedad y su uso común.

\section{b. Rama trasversal (mixta) de derecho}

El derecho deportivo no es basado únicamente sobre normas específicas sino también sobre un conjunto de normas de "derecho común", es decir destinadas a reglar un ámbito más amplio. Un ordenamiento jurídico - deportivo está conformado

\footnotetext{
${ }^{1}$ J. M. MARMAYOU, F. RIZZO, «Éditorial n. 1», CDS 1, Marseille le 28 mai 2005.
} 
fundamentalmente por normas jurídicas, unas de carácter general que si bien es cierto no regulan al deporte en sí, si inciden en este, cuando un club contrata a su personal o a sus jugadores, está sometido a las disposiciones contenidas en la legislación del trabajo, además está obligado a cumplir con las disposiciones tributarias. Los árbitros, deportistas, entrenadores, directores técnicos en el desempeño de sus actividades, están sujetos a las leyes civiles, laborales, penales, etc. ${ }^{2}$. Junto a estas normas generales, existen otras específicas que regulan al deporte, dispersas en varios ordenamientos jurídicos.

\section{c. Rama heterogénea de derecho}

Las normas deportivas tienen una naturaleza heterogénea (de origen no sólo público sino también privado), por lo que se refiere a su producción. Por eso, es importante presentar la teoría de heterogeneidad de la producción de reglas, de varias ramas de derecho.

\section{EL FENÓMENO DE HETEROGENEIDAD DE PRODUCCIÓN DEL DERECHO}

Durante los últimos años, muchos y varios nuevos títulos de manuales jurídicos aparecen en las vitrinas de las librerías de la ciencia jurídica, focalizando sobre especificas actividades sociales. Este movimiento se interpreta como prueba de la heterogeneidad del derecho, teoría que significa que existen dos diferentes fuentes de reglas de las ramas normativas. De un lado, existe la vía legislativa convencional, en la cual los competentes órganos del Estado son los protagonistas. De otro lado, existe una alternativa informal, dentro del ámbito de la sociedad. Las comunidades de profesionistas tienen frecuentemente la tendencia de producir las reglas que ellas consideran como favorables a sus propios intereses, frente a la intervención exterior de las autoridades estatales. El fenómeno de la producción de normas por los grupos de las profesiones y de los artes se interpreta como una forma de resistencia de la sociedad frente al legislador oficial, como derecho informal de autorregulación de los interesados.

Esta autorregulación puede tener lugar aún en el ámbito de la Administración pública, particularmente en campos de una libertad institucionalmente otorgada por el derecho convencional, ejemplificados por las Universidades o los organismos de autoadministración local. En otras palabras, aún las normas del derecho administrativo pueden tener una proveniencia informal y eventualmente oculta. Entonces, ese fenómeno rige el contenido de muchas nuevas ramas de derecho, aparecidas recientemente como el derecho ambiental, el derecho de la cultura, el derecho del consumidor y etc. La evolución de esas ramas es muy intensa y dotada con una celeridad a veces impresionante, como es el caso de la creación de la nueva rama del derecho climático en el ámbito del derecho ambiental.

Por lo que se refiere al derecho deportivo, es obvio que confirma la teoría de heterogeneidad ${ }^{3}$. Se trata de normas sea conocidas, como la tendencia de licenciar a los

\footnotetext{
${ }^{2}$ Z. FLORES FERNÁNDEZ, «Introducción al derecho deportivo. La relación entre el deporte y el Derecho», efdeportes.com, 15-143- Abril de 2010.

${ }^{3}$ D. PANAGIOTOPOULOS, Derecho Deportivo, Nomiki Vivliothiki Edición 2005 (en griego), p. 69.
} 
entrenadores de un modo extremamente fácil, particularmente a causa del simple hecho de algunas derrotas de los clubes, sin que ellos pidan la indemnización por la resta parte del tiempo de sus contractos de trabajo (o al menos un compromiso es muy habitual), o no.

Sin embargo, el derecho deportivo va más allá de la teoría de la heterogeneidad por lo que se refiere a la producción de las normas. Es notable que tiene tradicionalmente una proveniencia privada y muy raramente estatal mientras el fenómeno regido es producto de la sociedad. El rasgo de ésta rama es que el deporte no es meramente una actividad privada, de acción individual o colectiva, sino también el objeto de una regulación privada. Si uno querría compararla a otras nuevas ramas, como el derecho ambiental o de protección del consumidor, podría destacar unas diferencias importantes. Resulta que el derecho deportivo tiene una historia grande y una producción privada, de la sociedad interesada, no necesariamente de un grupo social de profesionistas. Se trata de una rama de internalización de grupos sociales más o menos amplios, o de una sociedad entera. Sin embargo, es tal el intervencionismo de las Administraciones y consecuentemente, la penetración del Derecho Administrativo y de los Poderes Públicos en el sector del Deporte en España - fenómeno extensible a otros ámbitos, conocido como "publificación', consecuencia de la "'hipertrofia" o "diarrea" legislativa a la que la sociedad española está sometida - que apenas existe un reducto de carácter enteramente privado, de autoorganización y autoregulación del Deporte ${ }^{4}$. Todo lo contrario a lo que sucede en otros lugares, como EEUU u ejemplos más cercanos como Reino Unido o Alemania, en los que el Deporte tiene naturaleza esencialmente privada. En materia de Grecia, ese país dispone de una legislación deportiva especial, de mayor intensión y extensión, en comparación con otros países europeos, como España, Francia, Italia, Portugal y etc ${ }^{5}$. Además, el fenómeno de la expansión del derecho público en áreas tradicionales del derecho privado ha sido típico de la modernización del derecho. Por ejemplo, la libertad contractual se ve cada vez más limitada, al punto de haberse creado contratos obligatorios, como el colectivo de trabajo, que, como el contrato - ley, se aplica aún a los que no fueran partes en su estipulación ${ }^{6}$.

\section{INTERNACIÓN E INTERNALICAZIÓN DEL DERECHO DEPORTIVO POR LA SOCIEDAD}

El derecho al deporte viene constituyendo una actitud histórica de las organizaciones deportivas particulares, rectoras en este ámbito, que ha llegado a tener la complicidad o tolerancia de los poderes públicos: la prohibición de que los miembros de las organizaciones deportivas acudan a vías externas (los órganos jurisdiccionales, por ejemplo) a impugnar las decisiones o actos que emanen de las mismas ${ }^{7}$. Esa actitud histórica se viene afincando en virtud de la afiliación obligatoria a tales organizaciones deportivas particulares a las que deben vincularse los practicantes para poder acceder a las competiciones.

\footnotetext{
${ }^{4}$ J. VALDÉS ESCALONA, «Derecho Deportivo vs. Derecho del Deporte», legaltoday.com, 21 de Mayo de 2014.

${ }^{5}$ A. MALATOS, Lecciones de Derecho Deportivo, Ediciones Ant. N. Sakkoula Atenas - Komotini 2010 (en griego), pp. 125.

${ }^{6}$ R. BARRAGÁN, Bosquejo de una Sociología del derecho, Universidad Nacional México, 1965, p. 91.

${ }^{7}$ K. L. PACHOT ZAMBRANA, «El derecho constitucional al deporte en la doctrina y el derecho comparado», CC, 2016-1, p. 138.
} 
Es notable que la jerarquía de los factores deportivos no es solamente privada sino también transnacional, con referencia al movimiento olímpico ${ }^{8}$. Las asociaciones de un deporte son reunidas en el marco de la Federación nacional, y esa es sometida a federaciones internacionales. Las federaciones mundiales son sometidas a la Comisión Olímpica Internacional. Acanto a la justicia, existe en el área de los deportes la "Justicia orgánica", la Justicia de los deportes, que incluye los juicios "jurisdiccionales" internos de los órganos de las asociaciones internacionales y nacionales ${ }^{9}$. Para la resolución de litigios a nivel internacional deportivo y a nivel olímpico es competente el Tribunal de Arbitraje Deportivo. Originalmente, fue creado para dirimir disputas durante los Juegos Olímpicos en 1984.

Es notable que el caso del comportamiento de Turquía en sus relaciones con Chipre (Estado no reconocido por ella) constituye una prueba del hecho de que el movimiento de deporte es dotado con una fuerza de imposición de sus normas, que es a veces superior a la fuerza de imposición de organizaciones más fuertes, tales como la Unión europea y las Naciones Unidas.

Además, muchas normas sobre el deporte tienen una proveniencia internacional, recientemente en materias relativamente originales, como es el caso del Convenio sobre la manipulación de competiciones deportivas, que se aprobó el 18 de septiembre de 2014, en el seno del Consejo de Europa ${ }^{10}$.

\section{LA CONSAGRACIÓN CONSTITUCIONAL IMPLÍCITA DEL DERECHO AL DEPORTE}

Como ya señalado, el derecho al deporte es muy estrictamente asociado al derecho clásico a las asociaciones de los privados, que pertenece a la primera generación de derechos fundamentales, compuesta de derechos civiles y políticos. Sería importante señalar que el derecho debe correlacionarse aún con el derecho al perseguimiento de la felicidad. Se trata de un derecho humano clásico, pero 'olvidado', reconocido en la Declaración de Independencia de los EEUU en 1776 mientras el fin de la 'felicidad de todos" existía en la Declaración de los Derechos del Hombre y del Ciudadano, aprobada por la Asamblea Nacional constituyente de Francia el 26 de agosto de 1789, sin incorporación explícita en los textos constitucionales posteriores.

En el período de entreguerras, una nueva generación emergió, los derechos económicos (trabajo, sindicalismo, huelga...), sociales y culturales. El derecho al deporte se considera como un derecho cultural, como la libertad del arte, el derecho a la educación etc. Sin embargo, es auténtico y separado, no absorbido por el derecho a la cultura u otros derechos similares como el derecho al ocio.

La primera tentativa de inclusión del deporte como un auténtico derecho fundamental social del hombre ocurrió en la Constitución de México en 1917. La negación del

\footnotetext{
${ }^{8}$ D. GOULAS, Relaciones laborales de deportistas, Ediciones Sakkoulas Atenas - Salónica, 2014 (en griego), p. 3.

9 D. PANAGIOTOPOULOS, «Derecho deportivo, Ordenamiento deportivo nacional e internacional», Independent Think Tank for Sciences and Society, julio 2016 (en griego).

${ }^{10}$ C. PÉREZ GONZÁLEZ, CARMEN, «A propósito de la acción del Consejo de Europa en el ámbito del deporte: Análisis del Convenio Europeo sobre la manipulación de competiciones deportivas», Eunomía. Revista en Cultura de la Legalidad, 8, marzo - agosto 2015, pp. 72.
} 
proyecto de ley tuvo un efecto devastador en este país, pasando desapercibido por muchos años hasta su completo y actual menosprecio ${ }^{11}$.

Correspondió a la Constitución de la Unión Soviética de 1936 la introducción por primera vez del hecho deportivo entre los contenidos básicos de un texto magno, cuando en su artículo 126, ubicado en el capítulo X 'Derechos y deberes fundamentales de los ciudadanos", al referirse al derecho a los ciudadanos a agruparse en organizaciones sociales, expresamente consignó, entre las mismas, a las deportivas ${ }^{12}$. El nuevo Estado de la Unión Soviética, pese a las importantes restricciones impuestas a los derechos humanos de ciudadanos en la práctica, quiso legitimarse mediante una Constitución dotada con derechos fundamentales como el deportivo. Según la teoría alemana de tres dimensiones potenciales de los derechos fundamentales, el derecho al deporte tiene una dimensión negativa, es decir de non intervención del Estado a la práctica eventual de los deportes por el individuo. No se trata meramente de un derecho civil sino de un derecho social, en el sentido de la obligación del Estado de otorgar a los interesados la facultad socioeconómica de hacer deportes. Resulta un derecho a doble naturaleza (civil y sobre todo social) y a contenido cultural. Las Constituciones no tenían la tendencia de hacer una consagración explicita del derecho al deporte mientras el término "derecho" se omitía aún por el fenómeno de educación física. Durante la etapa inicial, de sistematización indirecta del deporte en las constituciones (hasta 1968, cuando la constitución de la República Democrática Alemana explicitó el deporte entre sus contenidos), se comenzó a referenciar, más bien, la dimensión armónica e integral con que debía apreciarse la educación pública, incluyendo en su aspecto físico, pudiéndose entender el deporte como un medio de desarrollo de la misma.

Según el par. 2 del artículo 16 de la Constitución griega de 1975, la cultura (obviamente en el sentido de enseñanza) constituye una misión principal del Estado y tiene como objetivo (entre otros) la educación física de los griegos. Resulta que la gimnástica (educación física) constituye parte del procedimiento educativo de todos los grados del sistema de enseñanza.

Según el par. 9, "El deporte está bajo la protección y la supervisión superior del Estado. El Estado subvenciona y controla a las uniones de las asociaciones deportivas de todo género, según lo especificado por la ley. Ley también estipula la disposición de los reforzamientos dados cada vez a las uniones subvencionadas según su destinación".

Esta formulación 'neutral' es típica para la consagración constitucional de los derechos de segunda generación, dado que el legislador constitucional no querría introducir unas disposiciones claras sobre los derechos sociales de los privados. Sería menos difícil institucionalizar una competencia pública, aún en la forma de "obligación especial del Estado"' que normalmente es en plena conexión con el sugerido derecho de los interesados al disfrute de las actividades protegidas por las autoridades estatales. No es coincidencia que pese al hecho de que la segunda parte del texto constitucional griego tenía el título "'Derechos civiles y sociales", el principio del Estado social no fue explícitamente consagrado en una disposición, antes de la revisión de 2001. A través de esta revisión, que dio énfasis a la consagración de los derechos fundamentales, pero no al derecho al deporte, un principio tradicional, del Estado de derecho, y un principio constitucional más nuevo, conocieron su primera consagración explícita en la historia de

\footnotetext{
${ }^{11}$ L. SCH. DE BEM, «La constitucionalización del deporte», Anuario Iberoamericano de Derecho Deportivo, 2, 2011, p. 70.

${ }^{12}$ K. L. PACHOT ZAMBRANA, cit., pp. 123, 124.
} 
las Constituciones de Grecia. Siguiendo el ejemplo de la Constitución alemana, la griega hace mención del doble principio del Estado social de derecho ${ }^{13}$.

La doctrina ha formulado una crítica sobre el concepto de las Constituciones en materia de la relación entre el Estado y el deporte. Por lo que se refiere a la Constitución griega, la formulación adoptada reconoce el derecho clásico de erigir una asociación deportiva, de primer grado o de grado superior (unión de asociaciones), o de convertirse en miembro de ella.

Un derecho social (sugerido en forma de "obligación especial del Estado") ha sido introducido, no tanto como derecho social de cada persona sino como derecho civil (libertad de asociación) y social (es decir, sobre todo a las subvenciones públicas de las uniones de asociaciones) de las asociaciones deportivas (de primer grado o superior). Resulta un espíritu de paternalismo estatal, dado que el derecho social aparece como un derecho de acción colectiva (en forma de asociaciones) y sometida al control del Estado.

La Constitución sugiere que el poder público respecta al sistema de administración interna de las asociaciones de cada deporte, haciendo referencia a una supervisión superior y a un controlo del Estado mientras en el artículo 15 par. 1a impone el 'control directo" estatal sobre la radiodifusión y la televisión. En todo caso, donde existe 'control' (público), no hay libertad de la actividad privada sometida al control. Control y libertad de una institución son nociones contradictorias, no compatibles en el Derecho Constitucional!

Un nuevo concepto podría ser el inverso, frente al presente de la prevalencia de la autonomía de la voluntad privada (sometida a la legislación estatal). El Estado podría poner de manifiesto su voluntad de sostenimiento y protección del deporte $\mathrm{y}$ especificarla mediante la creación de un sistema legal de operación de cada sector deportivo pero ese sistema debería estar aprobado por los factores deportivos en el marco de la libre voluntad y de la autonomía privada ${ }^{14}$. El cumplimiento de la obligación constitucional para una intervención legislativa no debe interpretarse como coerción a través de la persuasión, de cada actividad privada, que es deportiva o se determina por sí misma como deportiva, de aceptar el sostenimiento y la protección que el Estado ofrece en materia de los deportes. Dado que la cooperación de los organismos deportivos y del Estado actualmente es obligatoria, sería mejor dependerse de la voluntad de esos organismos. Si algunos organismos rechazan el modelo de organización y operación del deporte, propuesto por las autoridades públicas, ellas son dotadas con medios y estructuras para proceder al cumplimiento de sus objetivos o encontrar a otros colaboradores - organismos deportivos para este propósito. Además, si cada organismo deportivo podría optar por acceder o no al modelo (propuesto por el Estado) de organización del deporte, fuera de ese modelo podrían operar todas las asociaciones que no lo aceptarían. Resulta que la práctica de non reconocimiento jurisdiccional de una federación deportiva (si hay ya en el sector del mismo deporte una federación reconocida por el poder judicial) debería terminar.

\footnotetext{
${ }^{13}$ P. BADURA, Staatsrecht Systematische Erläuterung des Grundgesetzes, 6. Auflage, C.H. Beck, 2015, S. 385.

${ }^{14}$ A MALATOS, cit., pp. 126-133.
} 


\section{LA CONSAGRACIÓN CONSTITUCIONAL EXPLÍCITA DEL DERECHO AL DEPORTE: DERECHO DE TERCERA GENERACIÓN}

Poco después de la doble introducción de los derechos fundamentales a la educación física y al deporte, en forma implícita, en el mismo artículo de la constitución griega, una nueva tendencia emergió. El reconocimiento expreso del deporte como derecho genuino y autónomo, susceptible de todas las consecuencias jurídicas que ello conllevará, se concretó precisamente en Latinoamérica, cuando en la Constitución cubana de 24 de febrero de 1976, en su entonces artículo 51, ubicado en el también entonces capítulo VI, denominado 'Derechos, deberes y garantías fundamentales', se reconoció, sin ambigüedad alguna, que: ' 'Todos tienen derecho a la educación física, al deporte y la recreación" "15. Pocos días después, la Constitución portuguesa estableció que todos tienen derecho a la cultura física y al deporte. La aparición constitucional del derecho al deporte fue un hecho reciente, siendo posteriormente extendido a Nicaragua (1986) y otros países. La positivación constitucional en Portugal es asociada a los hechos similares de Grecia, ya presentado, y de España (1978, artículos 43.3 y 148.19).

La nueva evolución, desde hace 1976, no podría verse únicamente como una perfección técnica y atrevida del movimiento de consagración, todavía implícita, del derecho al deporte. Se trata de una promoción histórica de un derecho (constitucional) cultural y social, de segunda generación, a un derecho multidimensional. El deporte se ha convertido, aunque quizá a nivel de subconsciencia inicialmente, en un ejemplo de derecho de tercera generación, a favor de los individuos, de los grupos sociales y de los pueblos.

Una parte de la doctrina sugiere que la dificultad de comprender al deporte como un derecho (derivado y no originario y autónomo, según la cual) la estriba en la indeterminación de su naturaleza, puesto que, desde su punto de vista, su materialización implica derechos cuya entidad es evidente, pero que devienen de generaciones diferentes, implicando el derecho de asociación (primera generación, como ya señalado), el derecho a la educación y a la vida cultural (segunda generación), e incluso, participando los derechos de solidaridad o de tercera generación. Otros escritores consideran al derecho al deporte como uno de la tercera generación, es decir sin hacer mención de un carácter derivado del derecho al deporte. Según la opinión opuesta, los derechos de solidaridad parten de problemáticas globales que necesitan de un enfoque transnacional para su concreción (como son los casos de los derechos a un medio ambiente sano, al agua, a la paz, al desarrollo, entre otros). Más bien el derecho al deporte involucra políticas públicas concretas e internas de los propios Estados que pretendan garantizarlo ${ }^{16}$.

Sin embargo, esta aproximación es estrecha dado que el fenómeno de los derechos de tercera generación tiene un contenido global y una dinámica compleja. Por ejemplo, la paz sigue siendo reivindicación compartida por culturas y civilizaciones, por pueblos y sociedades, en medio de una violencia tan amplia y extendida, no sólo por los conflictos bélicos sino por la desintegración social en donde organizaciones criminales y mafiosas ocupan el vacío que Estados fallidos o incompetentes no cubren para garantizar la

\footnotetext{
${ }^{15}$ K. L. PACHOT ZAMBRANA, cit., pp. 128, 126.

${ }^{16}$ K. L. PACHOT ZAMBRANA, cit., pp. 131-134.
} 
seguridad jurídica y la paz social de sus ciudadanos ${ }^{17}$. Como es natural, la paz ha sido incorporada en las constituciones como bien internacional y social. La aproximación precitada es estrecha también en materia del deporte. Por ejemplo, una partida amical podría tener lugar en muestra de solidaridad de un grupo social o de un pueblo hacia una persona, un grupo social o un pueblo en busca de apoyo. Las estancias por razones de entrenamiento o los encuentros deportivos, particularmente los internacionales, constituyen medios potenciales de cumplimiento de otros derechos de solidaridad, por ejemplo a la paz o al desarrollo. Además, la institución de tregua olímpica tiene que ver con la relación entre el deporte y el derecho humano a la non - violencia.

Se ve de la historia de la consagración explícita del "derecho al deporte" que ese, al menos por lo que se refiere al uso del término "derecho", pertenece al grupo de la tercera generación. En otras palabras, ejemplifica la categoría de los derechos consagrados después del comienzo de la octava década del siglo XX mientras el derecho similar a la educación física pertenece a la segunda generación, como podría considerarse el derecho al deporte en su versión implícita. Naturalmente, el derecho al deporte es estrechamente asociado al derecho emblemático de la tercera generación, es decir el derecho ambiental. Hacer deporte implica un contacto de los deportistas y las personas ayudantes (árbitros etc.) con el medio ambiente, paralelamente la educación física por definición se refiere al ambiente natural.

Sin reducir la importancia de las observaciones antecedentes, el derecho al deporte podría considerarse como un ejemplo emblemático de la categoría de los derechos de tercera generación, en sus ambos rasgos de solidaridad y de carácter colectivo (o comunitario). Se trata del fenómeno social de los aficionados que asisten no sólo a las partidas en casa de su equipo preferido sino más o menos a aquellas fuera de casa. La relación de los aficionados, socios oficiales o no del club, con el club es durable y solidaria, por definición. Ejemplifica también la noción del 'derecho colectivo" dado que tiene que ver con el interés común de una comunidad entera, no solamente de los socios del club oficial sino también de una sociedad que se identifica a través de ese club, y de las generaciones futuras de los socios. Esta aplicación sobre todo es relativa al equipo nacional de cada deporte, que dispone, como sostenedores, de los ciudadanos, en conjunto, de la nación interesada.

\section{EL DERECHO AL DEPORTE, LOS DERECHOS DE CUARTA GENERACIÓN Y LA PROYECCIÓN DE DERECHOS DE TERCERA GENERACIÓN}

Una parte de la doctrina ha hecho alude al derecho al deporte como prototipo de los derechos de una presumible cuarta generación, sin que haya explicado cuáles criterios metodológicos empleara para conceptuar esta "generación", 18. En realidad, existe una tal generación, cuyo ejemplo emblemático es el derecho a las tecnologías de información y comunicación. Un nuevo tipo de institución participa fundamentalmente

\footnotetext{
17 A. COLOMER VIADEL (coord..), Cultura de Paz y medidas para Garantizarlas, Ed. Nomos, Valencia, 2001.

${ }^{18}$ K. L. PACHOT ZAMBRANA, cit., p. 134, con referencia a A. ARÉVALO GUTIÉRREZ, y A. MARAZUELA BERMEJO, «El Consejo de Europa y el deporte», en PALOMAR OLMEDA, ALBERTO (coord..) et al., El modelo europeo del deporte, Barcelona, Bosch, 2002, p. 32.
} 
en este fenómeno ${ }^{19}$. Se trata de las comunidades de conocimientos: redes de individuos cuyo objetivo fundamental es la producción y la circulación de saberes nuevos y que ponen en relación a personas que pertenecen a entidades diferentes o incluso rivales.

Con la revolución de finales del siglo XX y principios del siglo XXI y la consecuente aparición de lo que se denomina Sociedad del Conocimiento, ha resultado necesario adoptar nuevas normas sobre el uso de las informaciones y la protección de los individuos frente a la publicación de sus datos personales. Hay un grupo aún en vía de reconocimiento, que incluye los derechos relativos a las manipulaciones biotecnológicas y la bioética y también al mundo de los animales ${ }^{20}$. Esta generación tiene un contenido obviamente asociado a las tecnologías de alto nivel pero no es ajena a la tendencia de una eventual creación de nuevos sujetos de derechos (el caso de los animales, del medio ambiente, de la especie humana) ${ }^{21}$. Por ejemplo, la Constitución del Ecuador, de 2008, es la única que reconoce derechos de la natura o "Pacha Mama' misma, aparte de los derechos humanos al ambiente y al agua.

Por supuesto, el derecho al medio ambiente constituye un derecho de la tercera generación que ha convertido a la bandera ecologista en una de las más universalizadas ante el temor de daño al planeta, por todos los abusos que los comportamientos económicos y sociales incontrolados están provocando ${ }^{22}$. Sin embargo, podría considerarse como derecho de la cuarta generación, por lo que se refiere a unas versiones específicas y unas tendencias jurídicas modernas, ejemplificadas por el derecho humano al disfrute y la protección de los animales y el derecho de protección frente al cambio climático. Por ejemplo, el derecho del cambio climático ya está adquiriendo su propia autonomía dentro del ámbito del derecho del ambiente ${ }^{23}$. Paralelamente, el ambiente constituye uno de los sectores de mayor incidencia del derecho de la Unión europea sobre el derecho de los estados miembros ${ }^{24}$.

En todo caso, no existen sólo los derechos de cuarta generación más o menos relativos al uso de las tecnologías, como los referidos y el derecho a la eficiencia energética particularmente de los edificios, sino el derecho ya señalado del perseguimiento de la felicidad. Este derecho recientemente ha sido el objeto de aproximación crítica por la comunidad académica ${ }^{25}$. Según una parte de la doctrina, la felicidad puede ser objeto de un derecho constitucional ${ }^{26}$. El derecho al perseguimiento de la felicidad constituye un '"nuevo derecho"' no reconocido explícitamente, basado en la teoría correspondiente del Derecho Constitucional Comparado ${ }^{27}$. Sin embargo, una parte de la doctrina es

${ }^{19}$ P. DAVID, D. FORAY, «Una introducción a la economía y a la sociedad del saber», Revista internacional de ciencias sociales, 171 marzo 2002.

${ }^{20}$ F. DEL GIUDICE, Compendio di Diritto Costituzionale, XX Edizione, Edizioni Giuridiche Simone, 2016, p. 102.

${ }^{21}$ A. V. CORNESCU, The generations of human's rights, Dny práva - 2009- Days of Law: the Conference Proceedings, 1. Edition. Brno: Masaryk University, 2009.

${ }^{22}$ A. COLOMER VIADEL, «Tendencias del Constitucionalismo en el Siglo XXI: Cuestionamientos e innovaciones constitucionales», TRC, núm. 36, 2015, p. 331.

${ }^{23}$ S. NESPOR, «I principi di Oslo: nuove prospettive per il contenzioso climatico», Giornale di diritto amministrativo, 6/2015, pp. 750-755.

${ }^{24}$ M. NUNZIATA, «I principi europei di precauzione, prevenzione e 'chi inquina paga"»', Giornale di diritto amministrativo 6/2014, p. 656.

${ }^{25}$ U. ECO, "La bustina di minerva Il diritto alla felicità", L'Espresso, 26 marzo 2014.

${ }^{26}$ G. GEMMA, 'Esiste un diritto costituzionale alla felicità?', $A F D S U D C, 12,2008$, p. 519.

${ }^{27}$ A. MANIATIS, 'The right to pursuit of happiness and Italian Tourism Law", Tourism Development Journal, 2017. 
claramente negativa en materia de un "derecho a la felicidad" o a la "serenidad", cuya versión sería el derecho a vacaciones serenas ${ }^{28}$.

Por lo que se refiere al deporte, se trata del objeto de un derecho de disfrute y del uso creativo del tiempo libre de los individuos. Es importante subrayar que la consagración expresa de ese derecho no ha adoptado el caso de Cuba, dotado con la introducción de un derecho de contenido más general, a la recreación.

Pese a esa omisión, un derecho inherente al ocio, el relativo al turismo, está en vía de reconocimiento. En el ámbito académico, mientras que algunos autores niegan que el turismo sea derecho humano, otro sector ha decidido considerarlo así ${ }^{29}$. El derecho al turismo está adquiriendo una posición constitucional, raramente explícita en Constituciones y todavía sobre todo implícita. Italia hacía referencia a la materia "turismo e industria de hoteles" en su Constitución de 1948 pero esta mención se omitió en la revisión de 2001, dato indicativo del carácter marginal de este derecho, aún en la era de la cuarta generación. El "'derecho al turismo"' se menciona en el artículo 7 del Código Ético Mundial para el turismo, aprobado en 1999 por la Asamblea General de la Organización Mundial del Turismo. La doctrina ha recientemente señalado que gracias a las nuevas evoluciones relativas a los medios de transportes (p. ej. avión, trenos a velocidad grande) y a la construcción de obras técnicas importantes, tales como puentes y túneles submarinas, un turista puede desplazarse de su residencia a una destinación turística en otro país y regresar a su residencia en un espacio temporal no mayor a 24 horas $^{30}$. Este plazo, si no superior, se considera en principio como elemento necesario de la noción del desplazamiento turístico pero ese concepto es atribuido meramente a razones de estadística ${ }^{31}$. Consecuentemente, los viajes internacionales, aún los diurnos, de los aficionados de los equipos deportivos ejemplifican no sólo el derecho al deporte sino sobre todo el derecho al turismo, en conclusión el derecho al ocio. En el siglo XXI el derecho de ser fan de un club deportivo ha adquirido una autonomía, a causa de varios factores, como la emersión precitada de la Sociedad del Conocimiento. Los privados pueden hacer uso de las nuevas tecnologías para informarse sobre los encuentros deportivos y para hacer apuestas relativas a esos. Resulta un doble derecho humano, por un lado el derecho tradicional de ejercer actividades deportivas y por otro lado el derecho relativamente nuevo de asistir a ellas, sobre todo a distancia (pero también como espectador, eventualmente en el cuadro particular de un desplazamiento turístico).

Si el derecho del turismo podría considerarse como "derecho constitucional" de cuarta generación, en el sentido de que su consagración en las constituciones formales, sea explícita sea implícita, es muy reciente, existen constituciones que no son dotadas con una garantía, al menos explícita, del deporte, todavía. Por ejemplo, la Constitución francesa no hace referencia al deporte, que tiene varias bases constitucionales, en el Preámbulo de la Constitución de 1946 (por lo que se refiere al ocio, al trabajo y a la educación ${ }^{32}$ ). La doctrina francesa en 2010 orientaba sus expectativas hacia el mecanismo apenas introducido de "Cuestión Prioritaria de Constitucionalidad"

\footnotetext{
${ }^{28}$ G. FERRO, 'Nuove frontiere della tutela del turista - consumatore nello spazio giuridico europeo e antiche diatribe domestiche; riflettendo sul c.d. "'danno da vacanza rovinata', Forum di Quaderni Costituzionali, 27 giugno 2014, n. 36.

${ }^{29}$ J. GASCÓN, 'Deconstruyendo el derecho al turismo', Revista CIDOB d'Afers Internacionals, n. 113, p. 55.

${ }^{30}$ D. MYLONOPOULOS, Derecho Turístico, Nomiki Vivliothiki 2011 (en griego), p. 5.

${ }^{31}$ R. VAINOPOULOS, S. MERCIER, Le tourisme, Le Cavalier Bleu Éditions 2009, p. 19.

32 J. MORANGE, «Sport et droits de l'homme », RJES 22, 1992-3, p. 3.
} 
examinada por el Consejo Constitucional, para la creación de un auténtico "derecho constitucional del deporte', 33 .

\section{CONCLUSIÓN}

En primer lugar, el deporte es consagrado como un derecho fundamental humano, pero en relación estricta con el derecho a educación (o cultura) física. Esencialmente, el derecho es doble, compuesto del derecho de hacer deportes y del derecho de la juventud a la educación física. Además, el derecho al deporte tiene un contenido doble en otro sentido, dado que incluye el derecho de los deportistas al ejercicio del deporte y el derecho de los restos interesados (árbitros, entrenadores, aficionados...) a la protección y la promoción del deporte. Ésta subdivisión (que tiene que ver también con el derecho a la educación física) es comparable con la distinción (inspirada por la formulación de Constituciones como la griega en el par. 1 del artículo 24) entre el derecho al ambiente y el derecho a la protección del ambiente ${ }^{34}$.

En todo caso, el régimen constitucional del deporte tiene un carácter "diacrónico", es decir correspondiendo a las tres últimas generaciones de derechos fundamentales mientras tiene también una relación directa con un derecho civil clásico de la primera generación (libertad de asociación). Es importante señalar que no solamente el deporte ha sido una institución que el Estado no querría consagrar, al menos a nivel de la Constitución, sino el derecho mismo a las asociaciones no fue fácilmente aceptado. Por ejemplo, ha sido considerado desde el comienzo como peligroso para el poder estatal en el ordenamiento constitucional griego y, por eso, su incorporación a la Constitución tuvo lugar tardíamente, en el artículo 11 de la Constitución de 1864, mientras su aplicación era dudable al menos hacia la adopción de la ley 281/1914 relativa a las asociaciones $^{35}$. En todo caso, existen constituciones que no han consagrado, al menos explícitamente, ese derecho, que pues hace parte de la materia de los "nuevos derechos" en esos ordenamientos nacionales, como es el caso de Francia, comparable con la omisión de los partidos políticos en la Constitución de Holanda ${ }^{36}$.

En segundo lugar, el deporte puede considerarse como una garantía institucional, es decir como una 'institución legal', reconocida y protegida por las Constituciones. Dada su importancia diacrónica, tiene una posición constitucional múltiple, ya que constituye una actividad social con un impacto precioso, en el ámbito privado y en aquel público de la vida de los ciudadanos. Los ciudadanos tienen derecho al ocio, mucho más al disfrute adecuado del ocio, y pues una actividad idónea sería la deportiva.

Pese al facto del carácter privado de los deportes, no es posible ignorar que se trata de una garantía institucional con impacto político, naturalmente implícito. En otras palabras, hacer deporte constituye una acción habitualmente colectiva. Esta forma de participación del pueblo está indirectamente asociada al principio de la democracia. La

\footnotetext{
${ }^{33}$ S. MARCILLOUX - GUIMMARRA, L'implicite mais réelle influence de la Constitution sur le droit du sport, VIII Congrès français de droit constitutionnel, AFDC, Nancy, 16, 17 et 18 juin 2011, p. 8.

${ }^{34}$ A. MANIATIS, «PPP and the constitutional right to the environment», Constitutionalism.gr , 20-112015.

${ }^{35}$ C. HRYSOGONOS, Derechos civiles y sociales, Nomiki Vivliothiki Edición 2006 (en griego), p. 493.

${ }^{36}$ H. SPOORMANS, I. BROEKHUIJSE, IRENE, «La regulación de los partidos políticos en Holanda», TRC núm. 35, 2015, p. 578.
} 
soberanía del pueblo es un principio que se aplica no sólo en la esfera estatal sino también en casi todos los sectores de la vida pública y privada. Desde hace las últimas décadas del siglo XX, el deporte se ha convertido en una actividad masiva, el ejercicio amateur del deporte es una conquista de la cultura occidental.

En tercer lugar, el deporte corresponde a las garantías constitucionales de nivel inferior, es decir a los casos precitados de los derechos fundamentales reconocidos en las Constituciones y a las garantías institucionales, y a los principios generales del derecho, positivados constitucionalmente. Se trata de la paz (non - violencia por los deportistas y los sostenedores de los clubes, tregua olímpica...), del principio ético de hacer deporte ("juego limpio"') etc. ${ }^{37}$

Finalmente, el derecho al deporte tiene que ver con el entero grupo de derechos fundamentales a la recreación. Pertenece a la subcategoría de los derechos relativos al movimiento humano, como los derechos al turismo y a la hospitalidad, mientras existe otra subcategoría, la cultural, que incluye el derecho a la cultura y aquello a la educación. Todos esos derechos específicos hacen parte del derecho general al derecho a la recreación, cuyo contenido es más amplio. En todo caso, el derecho a la recreación ejemplifica intrínsecamente e intensamente el derecho al perseguimiento de la felicidad.

\section{BIBLIOGRAFÍA}

ARÉVALO GUTIÉRREZ, y A. MARAZUELA BERMEJO, «El Consejo de Europa y el deporte», en PALOMAR OLMEDA, ALBERTO (coord..) et al., El modelo europeo del deporte, Barcelona, Bosch, 2002.

BADURA, Staatsrecht Systematische Erläuterung des Grundgesetzes, 6. Auflage, C.H. Beck, 2015, S. 385.

BARRAGÁN, Bosquejo de una Sociología del derecho, Universidad Nacional México, 1965.

COLOMER VIADEL (coord..), Cultura de Paz y medidas para Garantizarlas, Ed. Nomos, Valencia, 2001.

CORNESCU, The generations of human's rights, Dny práva - 2009- Days of Law: the Conference Proceedings, 1. Edition. Brno: Masaryk University, 2009.

DAVID, D. FORAY, «Una introducción a la economía y a la sociedad del saber», Revista internacional de ciencias sociales, 171 marzo 2002.

DEL GIUDICE, Compendio di Diritto Costituzionale, XX Edizione, Edizioni Giuridiche Simone, 2016.

ECO, “La bustina di minerva Il diritto alla felicità’, L'Espresso, 26 marzo 2014.

FERRO, ' 'Nuove frontiere della tutela del turista - consumatore nello spazio giuridico europeo e antiche diatribe domestiche; riflettendo sul c.d. 'danno da vacanza rovinata", Forum di Quaderni Costituzionali, 27 giugno 2014.

\footnotetext{
${ }^{37}$ F. VALENTI, «Lealtà sportiva. Etica e diritto», EJSS Journal 2014 2(2).
} 
FLORES FERNÁNDEZ, «Introducción al derecho deportivo. La relación entre el deporte y el Derecho», efdeportes.com, 15-143- Abril de 2010.

GEMMA, 'Esiste un diritto costituzionale alla felicità?', $A F D S U D C$, 12, 2008, p. 519.

GOULAS, Relaciones laborales de deportistas, Ediciones Sakkoulas Atenas - Salónica, 2014 (en griego).

HRYSOGONOS, Derechos civiles y sociales, Nomiki Vivliothiki Edición 2006 (en griego).

MALATOS, Lecciones de Derecho Deportivo, Ediciones Ant. N. Sakkoula Atenas Komotini 2010 (en griego).

MANIATIS, «PPP and the constitutional right to the environment», Constitutionalism.gr , 20-11-2015.

MANIATIS, "The right to pursuit of happiness and Italian Tourism Law", Tourism Development Journal, 2017.

MARCILLOUX - GUIMMARRA, L'implicite mais réelle influence de la Constitution sur le droit du sport, VIII Congrès français de droit constitutionnel, AFDC, Nancy, 16, 17 et 18 juin 2011.

MARMAYOU; RIZZO, «Éditorial n. 1», CDS 1, Marseille le 28 mai 2005.

MORANGE, «Sport et droits de l'homme », RJES 22, 1992-3.

MYLONOPOULOS, Derecho Turístico, Nomiki Vivliothiki 2011 (en griego).

NESPOR, «I principi di Oslo: nuove prospettive per il contenzioso climatico», Giornale di diritto amministrativo, 6/2015.

NUNZIATA, «I principi europei di precauzione, prevenzione e 'chi inquina paga"»', Giornale di diritto amministrativo 6/2014.

PACHOT ZAMBRANA, «El derecho constitucional al deporte en la doctrina y el derecho comparado», $C C$, 2016-1.

PANAGIOTOPOULOS, Derecho Deportivo, Nomiki Vivliothiki Edición 2005 (en griego).

PÉREZ GONZÁLEZ, CARMEN, «A propósito de la acción del Consejo de Europa en el ámbito del deporte: Análisis del Convenio Europeo sobre la manipulación de competiciones deportivas», Eunomía. Revista en Cultura de la Legalidad, 8, marzo agosto 2015.

SPOORMANS, I. BROEKHUIJSE, IRENE, «La regulación de los partidos políticos en Holanda», TRC núm. 35, 2015.

VAINOPOULOS, S. MERCIER, Le tourisme, Le Cavalier Bleu Éditions 2009.

VALDÉS ESCALONA, «Derecho Deportivo vs. Derecho del Deporte», legaltoday.com, 21 de Mayo de 2014. 